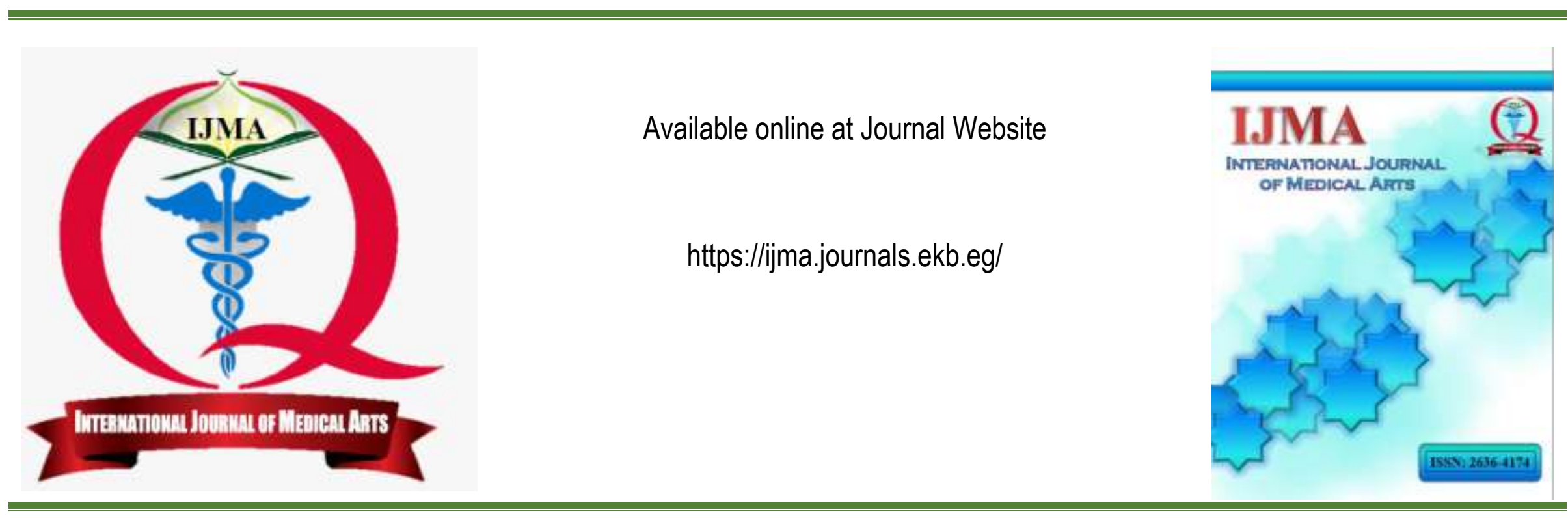

Original article

\title{
Awake fiberoptic versus awake videolaryngoscopy in difficult intubation
}

\author{
Saud Mohammed Erwia ; Ibrahim Fadl Mahmoudb; Neazy Abdmokhles Abdelmottalebb; \\ a Pulmonologist and Intensivist at Armed Forces Hospital, Jazan, Kingdom of Saudi Arabia; \\ ${ }^{b}$ Anesthesiology and Intensive Care Department, Faculty of Medicine, Al-Azhar University, New Damietta City, Egypt.
}

\author{
Corresponding author \\ Ibrahim Fadl Mahmoud \\ Anesthesiology and Intensive Care Department, \\ Faculty of Medicine, \\ Al-Azhar University, New Damietta, Egypt
}

Email: dr_ifm@yahoo.com

Received at: March, 30, 2019,

Revised at: May, 30, 2019

Accepted at: June, 15, 2019,

Available online at: June, 20, 2019.
Background: Difficult intubation is usually encountered in daily work of anesthesia and intensive care. Different inventions and techniques were tried to deal with difficult intubation.

Aim of the work: To investigate the difference between awake fiberoptic and awake videolaryngoscopy in difficult intubation

Methods: A two-years, randomized comparative study was conducted and included patients with ASA classes I to III, who were scheduled for elective surgical procedures with anticipated difficult intubation. Patient randomly allocated to fiberoptic intubation $(\mathrm{FI})$ and videolaryngoscopy (VL) intubation. The outcome measures were time to tracheal intubation, intubation success, number of attempts and operator evaluation of the procedure.

Results: Both groups were comparable as regard to patient demographics, ASA classifications, number of attempts and number of patients who experienced desaturation. The time to intubate was significantly shorter in VL when compared to FI group. The sedation score and ease scores were significantly lower in VL when compared to FI groups.

Conclusions: Videolaryngoscopy-guided intubation in difficult cases was associated with better outcome than fiberoptic intubation. However, no failure was reported in both groups

Keywords: Fiberoptic laryngoscope; Videolaryngoscopy; Difficult intubation; Hypoxemia.

\section{DOI: 10.21608/ijma.2019.36205}

This is an open access article under the Creative Commons license (CC BY) (https://creativecommons.org/licenses/by/2.0/) 


\section{Introduction}

Tracheal intubation is a routine technique in anesthesia and intensive care practice; its importance must not be under-appreciated. In some patients, tracheal intubation is difficult and responsible for a higher percentage of morbidity and mortality in anesthesiology. The French Society of Anesthesia and Intensive Care Medicine held a conference in 2006 on "difficult intubation", which chiefly dealing with assessment and management of risk of difficult intubation and the preventive measures of hypoxemia related to difficult intubation. After that, the introduction of new procedures, such as videolaryngoscopes, has guided the way for changes in practice ${ }^{[1]}$.

Difficult airway algorithms advocated awake endo-tracheal intubation as the gold standard for patients with difficult airway ${ }^{[2]}$.

Awake fiberoptic intubation is widely recommended for the management of difficult airway ${ }^{[3]}$. However, fiberoptic had some disadvantages, as it is a challenging maneuver to learn. Thus, continuous training is required to keep the skill ${ }^{[4]}$. In addition, the procedure is associated with risk like nasal bleeding, airway hyperreactivity, complete airway obstruction and oversedation $^{[5-6]}$. Furthermore, the technique requires satisfactory equipment, preparation of patients, and takes a significant amount of time to be done. All These factors may lead to the low use of fiberoptic intubation by many anesthetists ${ }^{[7]}$.

Videolaryngoscopes decrease the rate of Cormack and Lehane grade III and IV initially observed by direct laryngoscopy in cases with unanticipated difficult intubation. In these circumstances, the risk of failure of intubation in videolaryngoscopy-guided maneuver is low if practiced by an expert ${ }^{[8-9]}$.

In a multicenter study, accounting in 1427 failures with direct laryngoscopy, the videolaryngoscopy was described as the commonest backup technique in first-line by anesthetists. In this scenario, the success rate of intubation is more significant compared to other rescue appliances used in the same situation ${ }^{[10]}$. However, videolaryngoscopy may be complicated by trauma to upper airways or larynx especially if a stylet for the endotracheal tube was used ${ }^{[11]}$.

In the present work, we aimed to investigate the difference between awake fiberoptic and awake videolaryngoscopy in difficult intubation.

\section{Patients and methods}

A prospective, randomized comparative study was conducted during the last 2 years (January 2016 to January 2018). It was carried out at Al-Azhar University Hospital, and Armed Forces Hospital (Jazan). The study protocol was approved by the Local Research and Ethics Committee of Al-Azhar Faculty of Medicine (New Damietta) and Armed Forces Hospital (Jazan), and all patients provided an informed consent for participation in this work.

An adult patient with ASA class I to III, who scheduled for elective surgical procedures, and anticipated difficult intubation (modified SARI score $\geq 4)^{[12]}$ were recruited. Exclusion criteria included age less than 18 yearr, ASA class IV or V, mouth opening $<1.5 \mathrm{~cm}$, poor dental condition, surgeon request of nasal intubation as well as contraindication for transtracheal injection.

Laryngoscopy and intubation were done under sedation with preserved spontaneous breathing to escape situations with difficult mask ventilation. Randomization into two groups, fiberoptic intubation (FI) and videolaryngoscopy (VL) intubation was conducted in the operating room (open a closed envelope containing a number assigned for the group 1 for FI and 2 for VL) immediately before induction of anesthesia. Endotracheal tube and its size were selected before randomization. Patients in VL group were positioned in a sniffing position, whereas patient positioning used for FI was left to the preference of the operator. Atropine $0.4 \mathrm{mg}$, IV and midazolam $0.5-1 \mathrm{mg}$ I.V in boluses (and could be repeated up to $0.05 \mathrm{mg} / \mathrm{kg}$ ), 15 minutes before the procedure. We intended to reach a sedation score of 2-4 according to Ramsey sedation score.

All patients received standard Clinical care, monitoring by three lead ECG, non-invasive monitoring of blood pressure, pulse oximeter and Capnography. Oxygen (6L/minutes) were administered through nasal prongs. Each patient received nebulization with $5 \mathrm{ml}$ of lidocaine $2 \%$ for 15 minutes, followed by topicalization of soft palate and fauces by 5 puffs of lidocaine spray (10 $\mathrm{mg} /$ spray) immediately before the technique of intubation.

Before intubation, each patient received a bolus

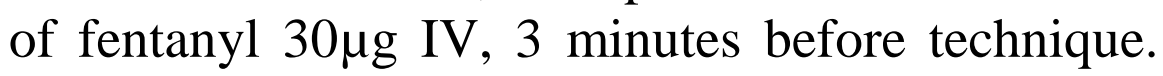
Patients then, were orally intubated with either the flexible fiberscope or the videolaryngoscopes. In case of FI, a Berman II intubation airway, size 8 or 9 was used for females and size 9 or 10 for males. An assistant carried out a jaw thrust to expand the oropharyngeal space. At intubation with the VL, a 
stylet was used to bend the tip of the tube $80-110^{\circ}$ into the shape of a hockey stick. Endotracheal tube placement was confirmed with capnography and bilateral auscultation. The primary endpoint was time to tracheal intubation (TTI) estimated from the advancement of the flexible fiberscope or the VL behind the teeth until the appearance of a capnograhy curve. It was determined by a stopwatch held by an observer not included in the study. Intubation success by the first attempt, number of attempts, failure of technique and or esophageal intubations were also documented. Finally, the operator evaluation of the ease of the procedure by visual analogue scale and potential complications were recorded.

Statistical Analysis: the collected data analyzed by the statistical package for social science (SPSS) version 21 (IBM ${ }^{\circledR}$, SPSS $\AA$; Chicago, Illinois, USA). Mean and standard devotion (SD) were calculated for numerical data; while frequency and percent was calculated for categorical data. Student (t) test, Mann-Whitney (U) test or Chi square were used for comparison between groups. $\mathrm{P}$ value $<0.05$ was set as a cutoff for significance.

\section{Results}

In the present work, age ranged from 40 to 68 years, while weight ranged from 69 to $92 \mathrm{~kg}$ and height ranged from 152 to $176 \mathrm{~cm}$. In addition, BMI ranged from 24.44 to $33.30 \mathrm{~kg} / \mathrm{m}^{2}$, and there were no significant differences between both groups as regard to age, weight, height or BMI. Males represented $54.3 \%$ of FI group compared to $55.7 \%$ of VL group with no significant difference. Furthermore, there was no significant difference between FI and VL groups as regard to ASA classification (Table 1). In addition, there was no significant difference between FI and VL groups as regard to BMI category, or any of airway evaluation parameters (For detailed results, see Table 2).

Regarding outcome, both groups were comparable as regard to number of attempts and number of patients who experienced desaturation. However, the time to intubate (TTI) was significantly shorter in VL when compared to FI group ( $84.85 \pm 22.14$ vs $134.07 \pm 33.43$ seconds). The sedation score and VAS score for ease of intubation was significantly lower in VL when compared to FI groups $(2.12 \pm 0.47,1.84 \pm 1.57$ vs $2.37 \pm 0.66$ and $2.60 \pm 1.86$ respectively). These data collectively indicate that, the videolaryngoscopy-guided intubation in difficult cases was associated with better outcome than FI, although no failure was reported in the present work in both maneuvers (Table 3).

Table (1): Patient characteristics

\begin{tabular}{|c|c|c|c|c|}
\hline \multicolumn{2}{|c|}{ Variable } & FI & VL & $\mathrm{P}$ value \\
\hline \multicolumn{2}{|c|}{$\begin{array}{c}\text { Age (mean } \pm \text { SD }) \\
\text { Range }\end{array}$} & $\begin{array}{c}51.85 \pm 6.78 \\
42-66\end{array}$ & $\begin{array}{c}51.90 \pm 7.05 \\
40-68\end{array}$ & 0.97 \\
\hline \multicolumn{2}{|c|}{$\begin{array}{c}\text { Weight }(\text { mean } \pm \text { SD) } \\
\text { Range }\end{array}$} & $\begin{array}{c}79.65 \pm 4.76 \\
73-89\end{array}$ & $\begin{array}{c}79.75 \pm 6.91 \\
69-92\end{array}$ & 0.92 \\
\hline \multicolumn{2}{|c|}{$\begin{array}{c}\text { Height }(\text { mean } \pm \text { SD }) \\
\text { Range }\end{array}$} & $\begin{array}{c}163.90 \pm 5.22 \\
153-176\end{array}$ & $\begin{array}{c}163.49 \pm 6.36 \\
152-174\end{array}$ & 0.67 \\
\hline \multicolumn{2}{|c|}{$\begin{array}{c}\text { BMI(mean+SD) } \\
\text { Range }\end{array}$} & $\begin{array}{l}29.66 \pm 1.36 \\
24.44-33.59\end{array}$ & $\begin{array}{l}29.78 \pm 0.86 \\
28.91-33.30\end{array}$ & 0.52 \\
\hline \multirow[t]{2}{*}{$\operatorname{Sex}(n, \%)$} & Male & $38(54.3 \%)$ & $39(55.7 \%)$ & \multirow[t]{2}{*}{0.86} \\
\hline & Female & $32(45.7 \%)$ & $31(44.3 \%)$ & \\
\hline \multirow{3}{*}{$\begin{array}{l}\text { ASA } \\
\text { Class }(n, \%)\end{array}$} & I & $3(4.3 \%)$ & $5(7.1 \%)$ & \multirow[t]{3}{*}{0.75} \\
\hline & II & $40(57.1 \%)$ & $38(54.3 \%)$ & \\
\hline & III & $27(38.6 \%)$ & $27(38.6 \%)$ & \\
\hline
\end{tabular}

SD: standard deviation; BMI: Body mass index; n: number; \%: percentage; ASA: American Society for Anesthesiologists 
Table (2): BMI and airway evaluation among studied populations

\begin{tabular}{|c|c|c|c|c|}
\hline \multicolumn{2}{|l|}{ Variable } & FI & VL & $\mathrm{P}$ value \\
\hline \multirow[t]{2}{*}{ BMI grade(n,\%) } & $25-30$ & $46(65.7 \%)$ & $50(71.4 \%)$ & \multirow[t]{2}{*}{0.46} \\
\hline & $>\mathbf{3 0}$ & $24(34.3 \%)$ & $20(28.6 \%)$ & \\
\hline \multirow[t]{2}{*}{ Mouth opening (n,\%) } & $\geq 4 \mathrm{~cm}$ & $46(65.7 \%)$ & $49(70.0 \%)$ & \multirow[t]{2}{*}{0.58} \\
\hline & $<4 \mathrm{~cm}$ & $24(34.3 \%)$ & $21(30.0 \%)$ & \\
\hline \multirow{3}{*}{$\begin{array}{l}\text { Thyromental } \\
(\mathrm{n}, \%)\end{array}$} & $\geq 6.5 \mathrm{~cm}$ & $58(82.9 \%)$ & $59(84.3 \%)$ & \multirow[t]{3}{*}{0.90} \\
\hline & 6-6.5cm & $9(12.9 \%)$ & $9(12.9 \%)$ & \\
\hline & $<6.5 \mathrm{~cm}$ & $3(4.3 \%)$ & $2(2.9 \%)$ & \\
\hline \multirow[t]{3}{*}{ Mallamati score $(\mathbf{n}, \%)$} & 1 & $3(4.3 \%)$ & $2(2.9 \%)$ & \multirow[t]{3}{*}{0.82} \\
\hline & 2 & $4(5.7 \%)$ & $3(4.3 \%)$ & \\
\hline & 3 & $63(90.0 \%)$ & $65(92.9 \%)$ & \\
\hline \multirow[t]{3}{*}{ Neck movement $(\mathrm{n}, \%)$} & $\geq 90^{\circ}$ & $27(38.6 \%)$ & $26(37.1 \%)$ & \multirow[t]{3}{*}{0.77} \\
\hline & $80-90$ & $9(12.9 \%)$ & $12(17.1 \%)$ & \\
\hline & $<80$ & $34(48.6 \%)$ & $32(45.7 \%)$ & \\
\hline \multicolumn{2}{|l|}{ Prognathism ability $(\mathrm{n}, \%)$} & $50(71.4 \%)$ & $42(60.0 \%)$ & 0.15 \\
\hline \multicolumn{2}{|c|}{ PH of difficult intubation $(n, \%)$} & $24(34.3 \%)$ & $28(40.0 \%)$ & 0.48 \\
\hline
\end{tabular}

BMI: Body mass index; n: number; \%: percentage; PH: past history

Table (3): Outcome among studied populations

\begin{tabular}{|l|c|c|c|c|}
\hline \multicolumn{2}{|c|}{ Variable } & FI & VL & P value \\
\hline TTI & & $134.07 \pm 33.43$ & $84.85 \pm 22.14$ & $<0.001 *$ \\
\hline Number of attempts & One & $43(61.4 \%)$ & $51(72.9 \%)$ & 0.25 \\
\cline { 2 - 5 } & Two & $26(37.1 \%)$ & $0(0.0 \%)$ & 0.06 \\
\cline { 2 - 5 } & Three & $1(1.4 \%)$ & $4(5.7 \%)$ & $0010 *$ \\
\hline Desaturation & & $11(15.7 \%)$ & $1.84 \pm 1.57$ & $0.014 *$ \\
\hline Ease score (VAS) & $2.60 \pm 1.86$ & $2.12 \pm 0.47$ & - \\
\hline Ramsey sedation score & $2.37 \pm 0.66$ & $0(0.0 \%)$ & \\
\hline Failure & $0(0.0 \%)$ & & \\
\hline
\end{tabular}

TTI: time to intubate; VAS:visual analogue score.

\section{Discussion}

Direct laryngoscopy has been the standard technique of airway management in anesthesia for decades. This maneuver depends on the ability of the operator to obtain a direct vision on the laryngeal inlet. This could not be achieved in every case, as there is many anatomical (e.g., small mouth), or pathological (e.g., laryngeal tumors) causes which make the intubation difficult to be completed with direct laryngoscope. Thus, an alternative technique should be considered ${ }^{[13]}$. 
The fourth National Audit Project (NAP) of the Royal College of Anesthetists and the Difficult Airway Society awake reported that, fiberoptic intubation is the gold standard for difficult intubation $^{[14]}$. However, clinical situations are not the same and the introduction of videolaryngoscopes in airway management questioned the use of awake fiberoptic intubation ${ }^{[15]}$.

Here, we examined the difference between awake fiberoptic and videolaryngoscopy in difficult intubation. Our results showed that, videolaryngoscopy is superior to fiberoptic intubation, as it was associated with significant reduction of time to intubation, decrease amount of sedatives, reduce sedation score and reported by operator to be significantly easier.

Results of the present work confirm previous studied revealed that, videolaryngo-scopes provide a better view than traditional laryngoscopes and are the first option or default device for some anesthetists ${ }^{[16-}$ ${ }^{20]}$. However, Ericsson ${ }^{[21]}$ stated that, regular training is needed to translate enhanced view into clinical success. Zaouter et al. ${ }^{[22]}$ confirmed this statement. Other researchers preferred the use of fiberscope especially in expert operators familiar with the use of this technology ${ }^{[23-25]}$.

In contradiction to results of the present work, Abdelmalak et al. ${ }^{[26]}$ reported that, in tracheal intubation with general anesthesia revealed nonsignificant difference between videolaryngoscopes and flexible fiberoptic bronchoscope, especially for time to intubate. The possible explanation for this difference can be attributed to the fact that, they included only obese patients and complete the intubation under general anesthesia. However, our results are in agreement with Levin et al. ${ }^{[27]}$ who reported that, fiberoptic bronchoscope for endotracheal intubation is a time-consuming technique than video-laryngoscopy; but, Heidegger et al. ${ }^{[28]}$ stated that, the time to intubate is operator dependent.

To explain long time for intubation by fiberoptic bronchoscope, Brull et al. ${ }^{[29]}$ reported that, in fiberoptic bronchoscopy, there is a difficulty to advance traditional polyvinylchloride tubes in up to $35 \%$ of patients, and Johnson et al. ${ }^{[30]}$ have reported higher rates of difficulty (53\%). This is an accepted explanation and results of the present work confirm this rationale.

The longer time of fiberoptic bronchoscopy in comparison to videolaryngoscopy was also confirmed in a systematic review and meta-analysis by Alhomary et al. ${ }^{[7]}$ with the time to intubation as the primary outcome of their meta-analysis. They demonstrated that, videolaryngoscopy is associated with a shorter intubation time compared with fiberoptic bronchoscopy.

In the present work, no failure of intubation after third trial was observed, and there was no significant difference between both techniques as regard to number of trials. These results are comparable to those reported by Abdelmalak et al ${ }^{[26]}$ who reported that, there was no superior technique to the other regarding successful intubation and the number of attempts.

The success rate in the present work in both techniques reflected the proficiency of the operators in both techniques, and this is supported previously in literature, where Pott et al. ${ }^{[31]}$ recommended that, anesthesiologists should become experts in more than one technique of intubation so that a substitute can be applied if the original approach fails.

Results of the present study revealed that, videolaryngoscopy was reported by operators to be easier than fiberoptic bronchoscopy. This is in contradiction to those reported by Rosenstock et al. ${ }^{[12]}$ who reported that, investigators assessed both videolaryngoscopy and fiberoptic intubation as easy to perform. They also found no significant difference in time to intubate. However, the success rate was significantly indifferent as in the present work.

In summary, videolaryngoscopy seems to be superior than fiberoptic intubation in awake difficult intubation.

\section{References}

1. Langeron O, Bourgain JL, Francon D, Amour J, Baillard C, Bouroche G, Chollet Rivier M, et al. Difficult intubation and extubation in adult anaesthesia. Anaesth Crit Care Pain Med. 2018;37(6):639-651.

2. American Society of Anesthesiologists Task Force on Management of the Difficult Airway: Practice guidelines for management of the difficult airway: An updated report by the American Society of Anesthesiologists Task Force on Management of the Difficult Airway. Anesthesiology 2003; 98: $1269-77$

3. Apfelbaum JL, Hagberg CA, Caplan RA, Blitt CD, Connis RT, Nickinovich DG, et al. Practice guidelines for management of the difficult airway: an updated report by the American Society of Anesthesiologists Task Force on management of the difficult airway. Anesthesiology 2013; 118(2):251-70. 
4. Fitzgerald E, Hodzovic I, Smith AF. 'From darkness into light': time to make awake intubation with videolaryngoscopy the primary technique for an anticipated difficult airway? Anaesthesia 2015; 70: 387-92.

5. Heidegger T, Gerig HJ, Ulrich B, Schnider TW. Structure and process quality illustrated by fibreoptic intubation: analysis of 1612 cases. Anaesthesia 2003; 58: 734-9.

6. Ho AM, Chung DC, To EW, Karmakar MK. Total airway obstruction during local anesthesia in a non-sedated patient with a compromised airway. Canadian Journal of Anesthesia 2004; 51: 83841.

7. Alhomary M, Ramadan E, Curran E, Walsh SR. Videolaryngoscopy vs. fibreoptic bronchoscopy for awake tracheal intubation: a systematic review and meta-analysis. Anesthesia. 2018; 73(9):1151-1161.

8. Asai T, Liu EH, Matsumoto S, Hirabayashi Y, Seo $\mathbf{N}$, Suzuki A, et al. Use of the Pentax-AWS in 293 patients with difficult airways. Anesthesiology 2009; 110:898-904.

09. Piepho T, Fortmueller K, Heid FM, Schmidtmann I, Werner C, Noppens RR. Performance of the C-MAC video laryngoscope in patients after a limited glottic view using Macintosh laryngoscopy. Anaesthesia 2011; 66:1101-5.

10. Aziz MF, Brambrink AM, Healy DW, Willett AW, Shanks A, Tremper T, et al. Success of intubation rescue techniques after failed direct laryngoscopy in adults: a retrospective comparative analysis from the multicenter perioperative outcomes group. Anesthesiology 2016; 125:656-66.

11. Lewis SR, Butler AR, Parker J, Cook TM, Smith AF. Videolaryngoscopy versus direct laryngoscopy for adult patients requiring tracheal intubation. Cochrane Database Syst Rev 2016;11 [CD011136].

12. Rosenstock CV, Thogersen B, Afshari A, Christensen AL, Eriksen C, Gatke MR. Awake fiberoptic or awake video laryngoscopic tracheal intubation in patients with anticipated difficult airway management: a randomized clinical trial. Anesthesiology. 2012 Jun;116(6):1210-6.

13. McCluskey C, Stephens M. Alternative techniques for tracheal intubation. Anesth Inten Care Med 2017; 18:4: 163-165

14. The fourth National Audit Project of the Royal College of Anaesthetists and the Difficult Airway Society. In: Major complications of airway management in the United Kingdom, report and findings. London: Royal College of Anaesthetists, 2011. Quoted from McCluskey C, Stephens M. Alternative techniques for tracheal intubation. Anesth Inten Care Med 2017; 18:4: 163-165

15. Kelly FE, Cook TM. Seeing is believing: getting the best out of videolaryngoscopy. Br J Anaesth 2016; 117(suppl 1): i9-13.

16. Niforopoulou P, Pantazopoulos I, Demestiha T, Koudouna E, Xanthos T. Video-laryngoscopes in the adult airway management: a topical review of the literature. Acta Anaesthesiol Scand 2010; 54: $1050-61$

17. Griesdale DEG, Liu D, McKinney J, Choi PT. Glidescope ${ }^{\circledR}$ video-laryngoscopy versus direct laryngoscopy for endotracheal intubation: a systematic reviewand meta-analysis. Can J Anaesth 2012; 59: 41-52

18. Andersen LH, Rovsing L, Olsen KS. GlideScope videolaryngoscope vs. Macintosh direct laryngoscope for intubation of morbidly obese patients: a randomized trial. Acta Anaesthesiol Scand 2011; 55: 1090-7

19. Mosier JM, Whitmore SP, Bloom JW, Snyder LS, Graham LA, Carr GE, et al. Video laryngoscopy improves intubation success and reduces esophageal intubations compared to direct laryngoscopy in the medical intensive care unit. Crit Care 2013; 17: R237

20. Aziz MF, Dillman D, Fu R, Brambrink AM. Comparative effectiveness of the C-MAC video laryngoscope versus direct laryngoscopy in the setting of the predicted difficult airway. Anesthesiology 2012; 116: 629-36

21. Ericsson KA. Deliberate practice and the acquisition and maintenance of expert performance in medicine and related domains. Acad Med 2004; 79: $\mathrm{S} 70-81$

22. Zaouter C, Calderon J, Hemmerling TM. Videolaryngoscopy as a new standard of care. $\mathrm{Br} \mathrm{J}$ Anaesth 2015; 114: 181-3

23. Kok T, George RB, McKeen D, Vakharia N, Pink A. Effectiveness and safety of the Levitan FPS ScopeTM for tracheal intubation under general anesthesia with a simulated difficult airway. Can J Anaesth 2012; 59: 743-50

24. Webb A, Kolawole H, Leong S, Loughnan TE, Crofts T, Bowden C. Comparison of the Bonfils and Levitan optical stylets for tracheal intubation: a clinical study. Anaesth Intensive Care 2011; 39: 1093-7 
25. Phua DS, Mah CL,Wang CF. The Shikani optical stylet as an alternative to the GlideScope ${ }^{\circledR}$ videolaryngoscope in simulated difficult intubations - $\mathrm{a}$ randomised controlled trial. Anaesthesia 2012; 67: 402-6

26. Abdelmalak BB, Bernstein E, Egan C, Abdallah R, You J, Sessler DI, Doyle DJ. GlideScope vs flexible fibreoptic scope for elective intubation in obese patients. Anaesthesia, 2011, 66, pages 550-555.

27. Levin R, Kissoon N, Froese N. Fibreoptic and videoscopic indirect intubation techniques for intubation in children. Pediatric Emergency Care 2009; 25 : 479.

28. Heidegger T, Starzyk L, Villiger CR, Schumacher S, Studer R, Peter B, et al. Fiberoptic intubation and laryngeal morbidity: a randomized controlled trial. Anesthesiology 2007; 107: 585-90.

29. Brull SJ, Wiklund R, Ferris C, Connelly NR, Ehrenwerth J, Silverman DG. Facilitation of fiberoptic orotracheal intubation with a flexible tracheal tube. Anesthesia and Analgesia 1994; 78: 746-8.

30. Johnson DM, From AM, Smith RB, From RP, Maktabi MA. Endoscopic study of mechanisms of failure of endotracheal tube advancement into the trachea during awake fiberoptic orotracheal intubation. Anesthesiology 2005; 102: 910-4.

31. Pott LM, Murray WB. Review of video laryngoscopy and rigid fiberoptic laryngoscopy. Current Opinion in Anesthesiology 2008; 21: $750-8$. 